Bulgarian Academy of Sciences. Space Research and Technology Institute.

Aerospace Research in Bulgaria. 29, 2017, Sofia

\title{
REVIEW OF SPECTRAL VEGETATION INDICES AND METHODS FOR ESTIMATION OF CROP BIOPHYSICAL VARIABLES
}

\author{
Ilina Kamenova, Lachezar Filchev, Iliana Ilieva \\ Space Research and Technology Institute - Bulgarian Academy of Sciences \\ e-mail: ilina.kamenova@hotmail.com, lachezarhf@space.bas.bg
}

\begin{abstract}
In present article a brief overview is presented on spectral vegetation indices and methods for estimation of crop main biophysical variables and their proxies. The main VIs used in estimation of nitrogen and chlorophyll, biomass, LAI and fAPAR, fCover, and photosynthesis are summarized.
\end{abstract}

\section{Biophysical variables and vegetation indices}

A number of techniques have evolved to derive the biophysical variables of vegetation using remote sensing data; these can be grouped into three broad categories: the inversion of radiative transfer models [39], machine learning (for example neural networks) [4] and the use of vegetation Indices. There are generally few ways of deriving the biophysical estimates using empirical or semi-empirical relationships: 1) single regression; 2) stepwise linear regression; 3) partial least squares (PLS) regression; 4) artificial neural networks [12]. Methods based on vegetation indices (VIs) have the benefit of being computationally simple while they are generally less site specific and more universally applicable than the other methods. The performance of the different indices and selected "optimal" wavebands depends on vegetation and land cover type, the variables to be retrieved, sun/view geometry to name but a few [12]. Satellite spectral data has the potential to measure the reflected radiation from many plants, thus making assessment of biophysical variables feasible on canopy level. The regression models relate in situ measurements and VIs. The VIs are mathematical transformations of the original spectral reflectance that are designed to reduce the additive and multiplicative errors associated with atmospheric effects, solar illumination, soil background effects, and sensor viewing geometry [29]. 


\section{Nitrogen and chlorophyll estimation}

Nitrogen is of particular interest in ecological and agricultural studies, because nitrogen availability can affect the rate of key ecosystem processes, including primary production [43]. Nitrogen has traditionally been considered one of the most important nutrients. It is an essential component of the proteins that build cell material and plant tissues. In addition, it is necessary for the function of other essential biochemical agents, including chlorophylls A and B; chloroplast enzymes of the Calvin cycle which are dominated by ribulose-1,5-bisphosphate carboxylase oxygenase (RuBisCO); high energetic compounds such as ATP and NADPH [15]; and the nucleic acids DNA and RNA. Nitrogen is often the most important determinant of plant growths and crop yield.

The productivity and dynamics of unmanaged terrestrial, most agricultural and forestry ecosystems are limited by the supply of biologically available nitrogen [43]. Although an artificial supply of nitrogen to crops is fundamental to optimize crop yields, mismanagement of $\mathrm{N}$ and its excessive application, causes many negative effects which have dramatically altered the global nitrogen cycle [32]. The effect of anthropogenic activities on the $\mathrm{N}$ cycle has been addressed to some extent. Europe has had some success using rules and fines to modify the fertilizer and animal farm waste. Educational programs need to be further developed to modify human behavior including the way farmers manage $\mathrm{N}$ fertilizers in their farms [42]. This challenge requires knowledge about the crop status.

On the other hand, chlorophyll content can directly determine the photosynthetic potential and primary production [16]. Chlorophylls can give an indirect estimation of the nutrient status, because part of the leaf nitrogen is incorporated in chlorophyll. Despite the relatively low N content of chlorophyll (4 mol /mol-1), strong correlations are found between chlorophylls and nitrogen in green leaves, because of the large amount of protein that complexes the photosynthetic pigment [15]. Furthermore, leaf chlorophyll content is indicative for health status evaluation and is closely related to plant stress [33].

\section{Vegetation indices for chlorophyll and nitrogen estimation}

A large number of spectral indices have been developed to measure chlorophyll content and nitrogen content. They were considered as a good estimator of these properties. The two variables are highly correlated; thus, they will be accessed with the same set of VIs. Still there are indices which better correlate with nitrogen and as well indices that better correlate with chlorophyll concentrations. The chlorophyll indices are utilizing the bands in the red-edge position which was proved by previous research $[6-10,28]$ to be particularly suitable for chlorophyll estimation. Because of the strong correlation between chlorophyll and nitrogen these indices are suitable for nitrogen as well. 
The SWIR bands are often mentioned in scientific literature as sensitive directly to nitrogen concentration. One of the Sentinel-2 main improvements over sensors as for instance Landsat TM, SPOT etc., are the bands centered on the Red Edge position. There are two Red Edge bands which are cantered at $705 \mathrm{~nm}$ and $740 \mathrm{~nm}$ with band width of $15 \mathrm{~nm}$. These wavelengths are essential for estimating biochemical quantities [9]. Most of the indices mentioned in the literature are developed initially as hyperspectral indices and cannot be calculated with the exact wavelengths as mentioned in the literature, as they require very specific bands, most of the cases not available by the Sentinel-2 MSI sensor bands. However, approximately close wavebands could be used to calculate indices.

Numerous VIs have been proposed for estimating canopy chlorophyll or nitrogen content [7]. Specifically, the red-edge region has been often used for estimating chlorophyll and nitrogen content. Vegetation indices often combine a near-infrared spectral band, representing scattering of radiation by a canopy, with a visible spectral band, representing absorption by chlorophyll. Problem with using the red spectral bands is the strong absorption by chlorophyll resulting into less sensitivity of such indices. Due to lower absorption by chlorophyll in the red-edge region, the use of such a band reduces the saturation effect, and the reflectance still remains sensitive to chlorophyll absorption at its moderate-to-high values [20]. For detecting plant stress the position of the red-edge inflection point is of very high significance [28]. The red-edge position has often been used as an estimate for chlorophyll content. With the number of red-edge bands of Sentinel-2 bands, the red-edge position can be derived by applying a simple linear model to the red-infrared slope [23].

Another type of index based on the MERIS red-edge bands is the MERIS terrestrial chlorophyll index, MTCI [9, 10]. This index has been applied successfully for many applications. It has been shown in various studies that ratio indices and/or normalized difference indices using red-edge bands perform very well in estimating chlorophyll or nitrogen content. Authors such as A. Gitelson [22] presented a ratio index based on a NIR band (e.g., at $800 \mathrm{~nm}$ ) and a red-edge band (e.g., at $710 \mathrm{~nm}$ ) for estimating chlorophyll content: the so-called red-edge chlorophyll index

(CIred-edge $=$ R800/R710-1). Similarly, a so-called green chlorophyll index $($ CIgreen $=\mathrm{R} 800 / \mathrm{R} 550-1)$ has been proposed. Major advantages are their linearity with chlorophyll content and absence of the saturation effect. In literature, various ratio indices can be found with slightly different band settings, often depending on the available sensor. The indices most often mentioned in the literature with significant results and suitable for calculation on Sentinel-2 bands are listed in Table 1. 
Table 1. Vegetation indices for chlorophyll and nitrogen estimation, suitable for calculation with Sentinel-2 bands

\begin{tabular}{|c|c|c|}
\hline Index & Formulae & References \\
\hline REP & $\left(\left(\left(\mathrm{R}_{670}+\mathrm{R}_{780}\right) / 2-\mathrm{R}_{700}\right) /\left(\mathrm{R}_{740}-\mathrm{R}_{700}\right)\right) * 40+\mathrm{R}_{700}$ & {$[6,7,23,44,45]$} \\
\hline MTCI & $\left(\mathrm{R}_{754}-\mathrm{R}_{709}\right) /\left(\mathrm{R}_{709}-\mathrm{R}_{681}\right)$ & {$[6,7,9,10,44]$} \\
\hline CI red edge & $\left(\mathrm{R}_{780} / \mathrm{R}_{709}\right)-1$ & {$[6,14,18,22,44]$} \\
\hline CI green & $\left(\mathrm{R}_{780} / \mathrm{R}_{550}\right)-1$ & {$[6,7,20]$} \\
\hline NDRE & $\left(\mathrm{R}_{740}-\mathrm{R}_{705}\right) /\left(\mathrm{R}_{740}+\mathrm{R}_{705}\right)$ & {$[20,41]$} \\
\hline NDRE1 & $\left(\mathrm{R}_{780}-\mathrm{R}_{705}\right) /\left(\mathrm{R}_{780}+\mathrm{R}_{705}\right)$ & {$[20,41]$} \\
\hline CCCI & $\left(\left(\mathrm{R}_{790}-\mathrm{R}_{720}\right) /\left(\mathrm{R}_{79} 0+\mathrm{R}_{720}\right)\right) /\left(\left(\mathrm{R}_{800}-\mathrm{R}_{670}\right) /\left(\mathrm{R}_{800}+\mathrm{R}_{670}\right)\right)$ & {$[2]$} \\
\hline
\end{tabular}

\section{Biomass estimation}

Measurement of various crop canopy variables during the growing season provides an opportunity for improving grain yields and quality by site-specific application of fertilizers and pesticides. Important variables in this context are the leaf area and total aboveground biomass because they are clear indicator of vegetation development and health [14, 31, 36, and 38]. The biophysical and biochemical parameters of plants are at the focus of many applications based on remote sensing techniques. Maps of those parameters are of particular interest to assist in the decision-making process in the context of agriculture. The biomass is one of the most important biophysical surface parameter attracting interest in wider researches concerned with earth observation data. The remote sensing techniques could provide repeated measures from a field without destructive sampling of the crop, which can provide valuable information for agricultural activities [27]. The repeated and consistent measurements result in the availability of time series data for a longer period of time. The availability of time series data for longer periods from different sensors helps the modern farmer to get current view on how a parcel performs over the growing season.

Spectral VIs derived from spectral reflectance have been shown to be useful for indirectly obtaining crop information such as biomass, photosynthetic efficiency, productivity potential, leaf chlorophyll content and $\mathrm{N}$ concentration [40]. Recent studies by $[5,11]$ have demonstrated the usefulness of optical indices from remote sensing in the assessment of vegetation biophysical and biochemical variables, including above ground biomass. In order to investigate the physical and biochemical parameters of a crop should be used VIs which are sensitive to the target characteristics of the crop parameters. Big challenge is also to evaluate the seasonal patterns of the VI and to determine which VIs are the most robust for detecting the biomass of the crop within a field over the growing season. 


\section{Vegetation indices for biomass estimation}

Remote sensing data and techniques have already proven to be used as a relevant tool for crop inventory and monitoring purposes [24, 25]. Among the different issues, determining the crop status, condition and biomass are some of the important issues in which remote sensing applications have been used [27]. Besides, crop parameters, such as leaf area index (LAI), leaf chlorophyll content, leaf water content, and canopy cover have been successfully measured using remote sensing technology, especially using spectral VIs [25, 26, and 29].

The simple ratio (SR) and the superior normalized difference vegetation index (NDVI), both calculated from measurements of the reflected light from the red and near infrared bands, have long been used as indirect measurement of biomass and crop yield, including that of wheat [14, 26, 27, and 38]. NDVI combining a near-infrared spectral band, representing scattering of radiation by a canopy, with a red spectral band, representing absorption by chlorophyll, saturates with higher LAI. This problem occurs because the red spectral band has very strong absorption by chlorophyll and that results into less sensitivity after certain value of LAI of such indices. Due to lower absorption by chlorophyll in the rededge region, the use of such a band reduces the saturation effect, and the reflectance still remains sensitive to chlorophyll absorption at its moderate-to-high values. Therefore, the red edge inflection point [18] and several NIR/NIR indices have been proven to offer more reliable signals in high biomass-producing areas like Europe. However, some indices concentrate on the visible range of the reflection spectrum. Because they are primarily influenced by the absorbance capacity of chlorophyll, VIS-based indices are presumed to identify green vegetation over soil, [17, 34].

NDVI have during the past decades been based on either broad wavebands (50-100 nm scale) from, e.g. the satellite-based Landsat Thematic Mapper using the TM-spectrometer (TM), or short wavebands (10 $\mathrm{nm}$ scale) from field-based spectroradiometers like FieldSpec (ASD Inc, PANalytical), CropScan MSR87 and MSR16 (CropScan, USA). The broadband VIs use, in principle, average spectral information over a wide range resulting in loss of critical spectral information available in specific narrow bands. To bridge that gap ESA's upcoming satellite Sentinel-2 (S2) aims to replace and improve the old generation of high resolution satellite sensors Landsat and SPOT, but with improved spectral capabilities. Of specific interest for remote sensing applications for agriculture monitoring are two new bands in the red edge (B5 at $705 \mathrm{~nm}$ and B6 at $740 \mathrm{~nm}$ ) [11]. The indices most often mentioned in the literature with significant results and suitable for calculation on Sentinel-2 bands are listed in Table 2. 
Table 2. VIs for biomass estimation, suitable for calculation with Sentinel-2 bands

\begin{tabular}{|c|r|c|}
\hline Index & Formulae & References \\
\hline NDVI & $\left(\mathrm{R}_{780}-\mathrm{R}_{670}\right) /\left(\mathrm{R}_{780}+\mathrm{R}_{670}\right)$ & {$[26,37,38]$} \\
\hline NDVI1 & $\left(\mathrm{R}_{740}-\mathrm{R}_{705}\right) /\left(\mathrm{R}_{740}+\mathrm{R}_{705}\right)$ & {$[26]$} \\
\hline NDVI2 & $\left(\mathrm{R}_{780}-\mathrm{R}_{705}\right) /\left(\mathrm{R}_{780}+\mathrm{R}_{705}\right)$ & {$[26]$} \\
\hline \multirow{3}{*}{ SR } & $\mathrm{R}_{740} / \mathrm{R}_{665}$ & \multirow{2}{*}{} \\
\cline { 2 - 3 } & $\mathrm{R}_{783} / \mathrm{R}_{665}$ & {$[14]$} \\
\cline { 2 - 3 } & $\mathrm{R}_{783} / \mathrm{R}_{740}$ & \\
\cline { 2 - 3 } & $\mathrm{R}_{783} / \mathrm{R}_{705}$ & {$[6,7,23,44,45]$} \\
\hline REP & $\mathrm{R}_{945} / \mathrm{R}_{865}$ & {$[14]$} \\
\hline VARI & $\left(\mathrm{R}_{550}-\mathrm{R}_{650}\right) /\left(\mathrm{R}_{550}+\mathrm{R}_{650}-\mathrm{R}_{470}\right)$ & \\
\hline
\end{tabular}

\section{LAI and fAPAR estimation}

With the advancement of RS technologies more scientific teams has started exploring satellite data to derive biophysical estimates for cereals and more specifically - winter wheat. Although many scientists have tried to transform their VIs in such a way that a linear relationship can be established between VI and the variable of interest, an exponential function still appears to be the best approximation [12]. The classical broadband vegetation indices typically use a spectral band in the red and one in the NIR. As both red and NIR reflectance saturate when LAI increases, the VIs become insensitive for dense canopies [25].

The Normalised Difference Vegetation Index (NDVI) [36] which is currently the most widely used VI as a measure for many variables. Although VIs such as the NDVI were primarily developed for the purpose of LAI retrieval they have also been argued to be capable of canopy chlorophyll content estimations [30]. Some authors have focused their efforts to linearize the relationship between the VIs in question and LAI [13]. On test-fields of winter wheat and rapeseed the DSIR760-R739 appeared to be the best estimate of LAI above 1.5 in terms of sensitivity compared to few other VIs.

\section{Fraction of vegetation cover (fCover) estimation}

Fraction of vegetation cover (fCover), or the percentage of soil surface covered by plant foliage (usually assessed vertically), is an important measurement of crop establishment and early vigor [35]. This variable can be related with the interception of solar radiation from crop canopies and thus with their production potential. Some times in the agronomic practice vegetation fraction as assessment from different view angle may be of interest. For example [3] suggest that an estimation of solar radiation interception at a $45^{\circ}$ view is more appropriate because 
it better represents an average sun angle. For wheat, however, the percent interception of total radiation changes little with time of day (sun angle) [3].

Typical approaches to measure fCover in the field are point quadrat techniques, visual assessment and digital analysis of photographs. These methods however do not have sufficient resolution or are laborious and time consuming. Thus, remote estimation through spectral vegetation indices is useful alternative. NDVI has long been regarded as a measure of the quantity of green vegetation covering the soil. [21] showed that NDVI is insensitive of fCover change in wheat when fCover $>60 \%$. Based on simulated MODIS bands these authors propose a simple index for estimation of wheat fCover - the Vegetation Index green (VI green). The relationship of this index with fCover is linear and $r^{2}>0.91$. Even better results are achieved with Visible Atmospherically Resistant Index green (VARI green) where blue band is used to reduce atmospheric effects. Modifications of NDVI have also been proposed. For example Wide Dynamic Range Vegetation Index (WDRVI) [19] outperforms VARI green in maize and soybean crops. Vegetation indices incorporating correction for soil reflectance also proved to be useful for wheat fCover estimation.

Table 3. Vegetation indices for chlorophyll and nitrogen estimation, suitable for calculation with Sentinel-2 bands

\begin{tabular}{|c|c|c|}
\hline Index & Formulae & References \\
\hline Red edge NDVI & $\left(\mathrm{R}_{\mathrm{NIR}}-\mathrm{R}_{\text {red edge }}\right) /\left(\mathrm{R}_{\mathrm{NIR}}+\mathrm{R}_{\text {red edge }}\right)$ & {$[19]$} \\
\hline WDRVI & $\left(0.3 * \mathrm{R}_{\mathrm{NIR}}-\mathrm{R}_{\mathrm{red}}\right) /\left(0.3 * \mathrm{R}_{\mathrm{NIR}}+\mathrm{R}_{\mathrm{red}}\right)$ & {$[19]$} \\
\hline VARI green & $\left(\mathrm{R}_{\text {green }}-\mathrm{R}_{\mathrm{red}}\right) /\left(\mathrm{R}_{\text {green }}+\mathrm{R}_{\text {red }}-\mathrm{R}_{\text {blue }}\right)$ & {$[21]$} \\
\hline VI green & $\left(\mathrm{R}_{\text {green }}-\mathrm{R}_{\mathrm{red}}\right) /\left(\mathrm{R}_{\text {green }}+\mathrm{R}_{\mathrm{red}}\right)$ & {$[21]$} \\
\hline
\end{tabular}

\section{Photosynthesis estimates}

Photosynthesis is the most important process in plants, but its measurement by gas exchange method (most accurate for now) is time consuming and requires specialized equipment. Vegetation products derived from terrestrial, airborne or satellite data for reflective characteristics of plants are more often used in agricultural practices to assess plant status and take the appropriate cultivation action.

The Photochemical Reflectance Index (PRI) (Table 4), calculated as (R531 - R570) / (R531 + R570) measures the activity of the xanthophyll cycle in plants - a process competitive of the electron transport in Photosystem II and thus closely correlated to the photosynthesis.

Articles that reported relationships between remotely sensed PRI and the following plant physiological variables - Light Use Efficiency (LUE) / Radiation Use Efficiency (RUE), $\mathrm{CO}_{2}$ uptake (Photosynthesis), actual photochemical 
efficiency of Photosystem II - ФPSII $=\Delta \mathrm{F} / \mathrm{Fm}^{\prime}$ and Non photochemical quenching (NPQ) were reviewed. For each article we registered the main features of the study, and also the correlation coefficient (Pearson's r) and the coefficient of determination $\left(\mathrm{R}^{2}\right)$ as indicators of the strength of each presented relationship.

Plants were grown at fields or in greenhouses and were exposed to different stresses (water deficit, nitrogen deficiency, cadmium pollution, etc.). Observations were organized on diurnal or through the whole vegetation cycle bases. Measurements were made on different plant organization levels-leaf, canopy or ecosystem ("canopy" refers to either a single plant or a monospecific stand, and "ecosystem" refers to a mixed-species stand). The index PRI isn't suitable for calculation using Sentinel-2 imagery and bands combinations aren't possible. On this stage no modeling of photosynthesis parameters is planned. For future research we see the exploration of those parameters and the vegetation fluorescence as a very promising initiative, especially in line with the Sentinel-3 mission and the development of FLuorescence EXplorer (FLEX) from ESA.

Table 4. Vegetation indices for photosynthesis parameters estimation, suitable for calculation with Sentinel-2 bands

\begin{tabular}{|c|l|l|}
\hline Index & Formulae & \multicolumn{1}{|c|}{ References } \\
\hline PRI & $\left(\mathrm{R}_{531}-\mathrm{R}_{570}\right) /\left(\mathrm{R}_{531}+\mathrm{R}_{570}\right)$ & $\begin{array}{l}\text { wheat (Magney et al., 2014); barley (Filella et al., } \\
1996 \text { and Sun et al., 2013); rice (Inoue et al., 2008); } \\
\text { maize (Cheng et al., 2013, Panigada et al., 2014, } \\
\text { Rossini et al., 2013, Rossini et al., 2015); soybean } \\
\text { (Inamullah and Isoda, 2005, Xue et al., 2014); } \\
\text { sunflower (Magney et al., 2014, Peñuelas et al., 1994); } \\
\text { grass (Rossini et al., 2012) and different species } \\
\text { including herbaceous annuals, deciduous perennials } \\
\text { and evergreen perennials (Gamon et al., 1997) }\end{array}$ \\
\hline
\end{tabular}

\section{Acknowledgements}

Present study is implemented within contract Testing Sentinel-2 vegetation indices for the assessment of the state of winter crops in Bulgaria (TS2AgroBg). The Project is funded by the Government of Bulgaria through an ESA Contract (4000117474/16/NL/NDe) under the PECS (Plan for European Cooperating States). The view expressed herein can in no way be taken to reflect the official opinion of the European Space Agency.

\section{References}

1. Aschbacher, J., and M. P. Milagro-Pérez. The European Earth Monitoring (GMES) Programme: Status and Perspectives. 2012, 120, 3-8. 
2. Barnes, E. M., et al. Coincident detection of crop water stress, nitrogen status and canopy density using ground based multispectral data. Proceedings of the 5th Inter. Conf. on Precision Agri., Bloomington, MN, USA. 2000, 1619.

3. Bell, M. A., and R. A. Fischer, Using yield prediction models to assess yield gains: A case study for wheat. Field Crops Research, 1994, 36, 2, 161-66.

4. Carpenter, G. A., et al. A neural network method for efficient vegetation mapping." Remote Sensing of Environment, 1999, 70, 3, 326-338.

5. Chen, P. et al. New Spectral Indicator Assessing the Efficiency of Crop Nitrogen Treatment in Corn and Wheat. Rem. Sens. of Env., 2010, 114, 9, 1987-97.

6. Clevers, J. G. P. W., and A. A. Gitelson. Remote Estimation of Crop and Grass Chlorophyll and Nitrogen Content Using Red-Edge Bands on Sentinel-2 and -3. Inter. J Applied Earth Observation and Geoinformation, 2013, 23, 344-51.

7. Clevers, J. G.P.W., and L. Kooistra. Using Hyperspectral Remote Sensing Data for Retrieving Canopy Chlorophyll and Nitrogen Content, 2012, 5, 2, 574-83.

8. Curran, P. J., W. R. Windham, and H.L. Gholz, Exploring the Relationship between Reflectance Red Edge and Chlorophyll Concentration in Slash Pine Leaves. Tree physiology, 1995, 15, 3, 203-6.

9. Dash, J., and P. J. Curran, The MERIS Terrestrial Chlorophyll Index. Int. J. Rem. Sens., 2004, 25, 23, 5403-13. DOI: 10.1080/0143116042000274015

10. Dash, J., and P.J. Curran, Evaluation of the MERIS Terrestrial Chlorophyll Index (MTCI). Advances in Space Research, 2007, 39, 1, 100-04.

11. Delegido, J., J. Verrelst, L. Alonso, and J. Moreno. Evaluation of Sentinel-2 Red-Edge Bands for Empirical Estimation of Green LAI and Chlorophyll Content. Sensors, 2011, 11, 7, 7063-81.

12. Dorigo, W. A. et al. A Review on Reflective Remote Sensing and Data Assimilation Techniques for Enhanced Agroecosystem Modeling. International Journal of Applied Earth Observation and Geoinformation, 2007, 9, 2, 165-93.

13. Elvidge, C. D., and Chen, Z. Comparison of broad-band and narrow-band red and nearinfrared vegetation indices. Rem. sens. of envir., 1995, 54, 1, 38-48.

14. Erdle, K., B. Mistele, and U. Schmidhalter, Comparison of Active and Passive Spectral Sensors in Discriminating Biomass Parameters and Nitrogen Status in Wheat Cultivars. Field Crops Research, 2011, 124, 1, 74-84. DOI: $10.1016 /$ j.fcr.2011.06.007

15. Evans, J. R. Photosynthesis and Nitrogen Relationships in Leaves of C3 Plants. Oecologia, 1989, 78, 1, 9-19. DOI: 10.1007/BF00377192

16. Filella, I., L. Serrano, J. Serra, and J. Peñuelas. Evaluating Wheat Nitrogen Status with Canopy Reflectance Indices and Discriminant Analysis. Crop Science, 1995, 35, 5,1400 .

17. Gamon, JAm, L. Serrano, and J. S. Surfus. The photochemical reflectance index: an optical indicator of photosynthetic radiation use efficiency across species, functional types, and nutrient levels. Oecologia, 1997, 112, 4, 1997, 492-501.

18. Gitelson, A. A. et al. Remote Estimation of Canopy Chlorophyll Content in Crops. Geophysical Research Letters, 2005, 32, 8, 1-4. DOI: 10.1029/2005GL022688

19. Gitelson, A. A. Remote estimation of crop fractional vegetation cover: the use of noise equivalent as an indicator of performance of vegetation indices. International journal of remote sensing, 2013, 34, 17, 6054-66. 
20. Gitelson, A. A., Y. J. Kaufman, and M.N. Merzlyak. Use of a Green Channel in Remote Sensing of Global Vegetation from EOS-MODIS. Remote Sensing of Environment, 1996, 58, 3, 289-98.

21. Gitelson, A. A., Y. J., Kaufman, R., Stark, and D. Rundquist, Novel algorithms for remote estimation of vegetation fraction. Remote sensing of Environment, 2002, $80,1,76-87$.

22. Gitelson, A. A., G. P. Keydan, and M.N. Merzlyak. Three-Band Model for Noninvasive Estimation of Chlorophyll, Carotenoids, and Anthocyanin Contents in Higher Plant Leaves. Geophysical Research Letters, 2006, 33, 11, L11402. DOI: 10.1029/2006GL026457

23. Guyot, G., and F. Baret. Utilisation de La Haute Resolution Spectrale Pour Suivre L'etat Des Couverts Vegetaux. 1988, 287, 279.

24. Haboudane, D. et al. Integrated Narrow-Band Vegetation Indices for Prediction of Crop Chlorophyll Content for Application to Precision Agriculture. Rem. Sens. of Envir., 2002, 81, 2-3, 416-26. DOI: 10.1016/S0034-4257(02)00018-4

25. Haboudane, D. et al. Hyperspectral Vegetation Indices and Novel Algorithms for Predicting Green LAI of Crop Canopies: Modeling and Validation in the Context of Precision Agriculture. Rem. Sens. of Env., 2004, 90, 337-52.

26. Hansen, P. M., and J. K. Schjoerring. 2003. Reflectance Measurement of Canopy Biomass and Nitrogen Satus in Wheat Crops Using Normalized Difference vegetation indices and Partial Least Squares Regression. Rem. Sens. of Envir., 86, 4, 542-53. DOI: 10.1016/S0034-4257(03)00131-7

27. Hatfield, J. L., and J. H. Prueger. 2010. Value of Using Different Vegetative Indices to Quantify Agricultural Crop Characteristics at Different Growth Stages under Varying Management Practices. 2, 2, 562-78.

28. Horler, D. N. H., M. Dockray, and J. Barber. The Red Edge of Plant Leaf Reflectance. Int. J. Rem. Sens., 1983, 4, 2, 273-88. DOI: 10.1080/01431168308948546

29. Huete, A. et al. Overview of the Radiometric and Biophysical Performance of the MODIS Vegetation Indices. Rem. Sens. of Envir., 2002, 83, 1, 195-213. DOI: 10.1016/S0034-4257(02)00096-2

30. Huete, A. R. A Soil-Adjusted Vegetation Index (SAVI). Rem. Sens. of Envir., 1988, 25, 3, 295-309. DOI: 10.1016/0034-4257(88)90106-X

31. Jamieson, P.D., M.A. Semenov, I.R. Brooking, and G.S. Francis. Sirius: A Mechanistic Model of Wheat Response to Environmental Variation. Europ. J. Agro., 1998, 8, 161-79. DOI: 10.1016/S1161-0301(98)00020-3

32. Keeney, D. R., and J. L. Hatfield. The Nitrogen Cycle, Historical Perspective, and Current and Potential Future Concerns. In Elsevier Inc., 2008, 1-18.

33. Merzlyak, M. N., A. A. Gitelson, O. B. Chivkunova, and V. YU. Rakitin. NonDestructive Optical Detection of Pigment Changes during Leaf Senescence and Fruit Ripening. Physiologia Plantarum, 1999, 106, 1, 135-41. DOI: 10.1034/j.1399-3054.1999.106119.x

34. Peñuelas, J., J. A. Gamon, A. L. Fredeen, J. Merino, \& C. B. Field, Reflectance indices associated with physiological changes in nitrogen-and water-limited sunflower leaves. Rem. sens. of Envir., 1994, 48, 2, 135-146.

35. Pask, A. J. D., Pietragalla, J., Mullan, D. M., and M.P. Reynolds, Physiological breeding II: a field guide to wheat phenotyping. 2012, Cimmyt. 
36. Pimstein, A. et al. A Spectral Index to Monitor the Head-Emergence of Wheat in SemiArid Conditions. Field Crops Research, 2009, 111, 3, 218-25.

37. Rouse Jr, J., Haas, R. H., Schell, J. A., and Deering, D. W. (1974). Monitoring vegetation systems in the Great Plains with ERTS.

38. Serrano, L., I. Filella, J. Peñuelas. Remote Sensing of Biomass and Yield of Winter Wheat under Different Nitrogen Supplies. Crop Sci., 2000, 40, 3, 723. DOI: 10.2135/cropsci2000.403723x

39. Shultis, J. K., and R. B. Myneni. Radiative transfer in vegetation canopies with anisotropic scattering. J Quant. Spectro. and Radiat. Transf., 1988, 39, 2, 115-29. DOI: 10.1016/0022-4073(88)90079-9

40. Thenkabail, P. S, R. B. Smith, E. De Pauw, Hyperspectral Vegetation Indices and Their Relationships with Agricultural Crop Characteristics. Rem. Sens. of Envir., 2000, 71, 2, 158-82. DOI: 10.1016/S0034-4257(99)00067-X

41. Tilling, A. K., et al. Remote sensing of nitrogen and water stress in wheat. Field Crops Res., 2007, 104, 1-3, 77-85. DOI: 10.1016/j.fcr.2007.03.023

42. Tilman, D. et al. 2002. Agricultural Sustainability and Intensive Production Practices. Nature, 418, 6898, 671-77. DOI: 10.1038/nature01014

43. Vitousek, P. M., and R. W. Howarth. Nitrogen Limitation on Land and in the Sea: How Can It Occur? Biogeochem, 1991, 13, 2. DOI: $10.1007 / B F 00002772$

44. $\mathrm{Wu}, \mathrm{C}$., et al. Remote estimation of gross primary production in wheat using chlorophyll-related vegetation indices. Agri. and Forest Meteorol., 2009, 149, 6-7, 1015-21. DOI: 10.1016/j.agrformet.2008.12.007

45. Wu, C., et al. Estimating chlorophyll content from hyperspectral vegetation indices: Modeling and validation. Agricultural and forest meteorology, 2008, 148, 8-9, 1230-41. DOI: 10.1016/j.agrformet.2008.03.005

\section{ОБЗОР НА ИНДЕКСИТЕ И МЕТОДИТЕ ЗА ИЗСЛЕДВАНЕ НА БИОФИЗИЧНИ ПРОМЕНЛИВИ НА ЗЕМЕДЕЛСКИ КУЛТУРИ}

\section{И. Каменова, Л. Филчев, И. Илиева}

\section{Резюме}

В настоящата статия е представен кратьк обзор на вегетационните индекси и методите за оценка на основните биофизични променливи на земеделски култури. Направена е характеристика на основните вегетационни индекси, използвани при оценката на азот и хлорофил, биомаса, листов индекс и fAPAR, fCover и фотосинтеза. 